\title{
What brings us together?
}

Written by: Angel Gurría, Secretary-General of the OECD

Last update: 28 January 2020

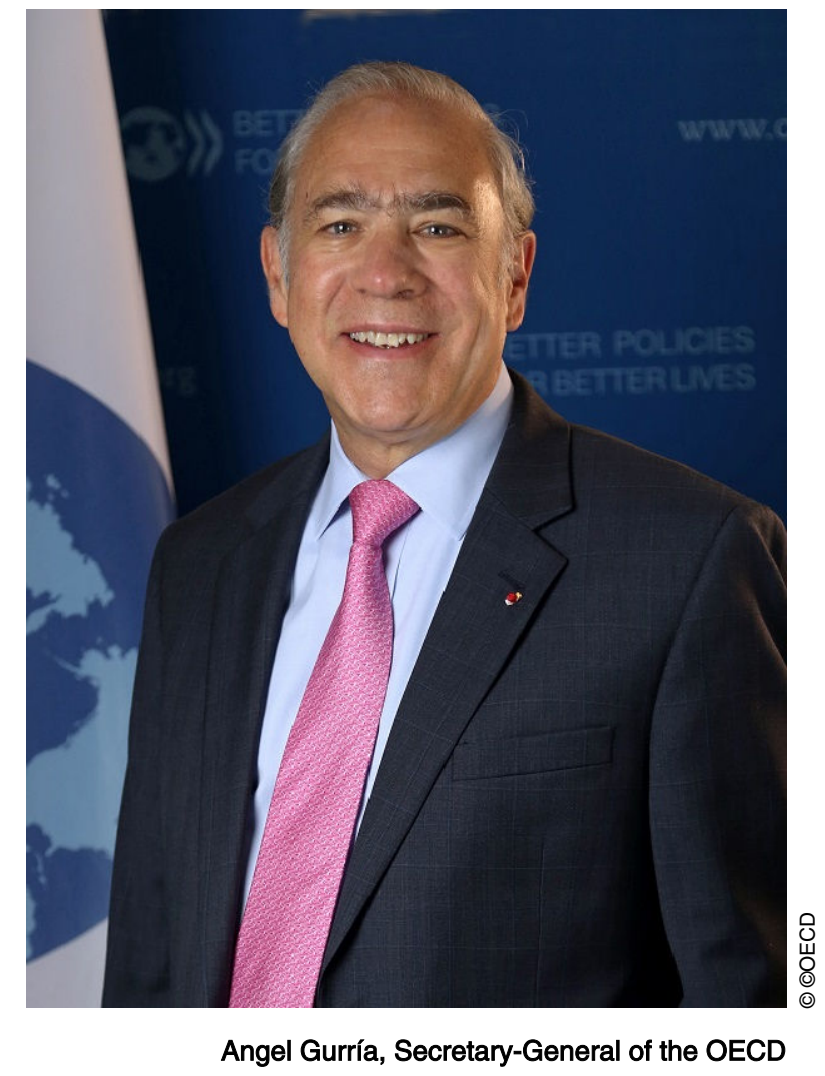

We all come from different corners of the world, from different backgrounds, times and professions. We carry different cultures and stories, different concerns and life expectations, different hopes and fears.

What brings us together today is a belief, a conviction, a certainty that multilateralism is needed more than ever. We agree that in a globalised, interdependent world, international co-operation is the most enlightened way to improve our wellbeing, perhaps the only one. We are facing challenges that none of us can solve on their own. Our countries are connected; our destinies interwoven; our solutions entangled. In the words of Dostoyevsky: "We are all responsible to all for all." 
But it's also time to ask ourselves why these pushbacks, why these "antibodies" to our common cause, are emerging. It's time to recognise that something is not working when the world's richest $1 \%$ accumulate half of the world's wealth; when more than $60 \%$ of the world's employed work informally; when the richest $10 \%$ of the OECD population now earn almost 10 times more than the poorest $10 \%$, up from 7 times in the 1980s; and when trust in governments, institutions, political parties, banks, enterprises and international organisations has decreased to record lows.

Why? Because national and global economic systems keep leaving too many behind. Thus, we need to rethink and relaunch international co-operation. Multilateralism has delivered and is delivering in hundreds of fronts: think of hunger, extreme poverty, aids, malaria, child labour, the Sustainable Development Goals (SDGs), the Paris Climate Agreement. Here at the OECD we have reached remarkable agreements on tax transparency, BEPS, anti-bribery, better corporate governance and responsible business conduct, to name just a few.

We are also advancing new major multilateral initiatives to make globalisation more humane, such as the Inclusive Growth Framework and the New Jobs Strategy. Our collaboration with the G20 has grown over the years, helping us bring large emerging economies to adopt OECD standards on tax, corporate governance, investment; we have also reached crucial deals on women's empowerment and steel over-production, to mention a few. A lot is already being achieved multilaterally!

However, more needs to be done to make multilateralism more effective, more transparent, more inclusive and more trustworthy. We also need to ensure effective implementation of our international standards to level the global playing field. The OECD has developed close to 450 multilateral legal instruments since its creation. More than half of these remain in force today. To keep them relevant we launched an OECD-wide Standard Setting Review to make sure that the OECD legal instruments continue to respond to the challenges faced by governments.

We need to strengthen our commitment to inclusive growth and put it at the heart of the multilateral system. In spite of recent improvements, inequalities continue to increase, blighting people's lives, wasting their potential contribution, eroding their trust in democracy. This is unfair, politically dangerous, and corrosive for our economies. Our work shows that inequalities reduce aggregate productivity and growth because they reduce the capacity of the poorest $40 \%$ to invest in the education and skills of their children.

This OECD Forum is an opportunity to discuss the impacts and enormous potential of digitalisation. Digitalisation and its offspring-social networks, artificial intelligence, big data, the "internet of things"-are rapidly changing all facets of our societies and economies. Our Going Digital Project and the new OECD 
Jobs Strategy are taking a "deep dive" into such questions to advance our understanding of these new technologies and give policymakers evidence and policy options to widen connectivity, strengthen cybersecurity and make the most of the digital economy.

In one of his most emblematic and multicultural books, The Enchantress of Florence, Salman Rushdie wrote: "This may be the curse of human race. Not that we are so different from one another, but that we are so alike." And I say: nice shot Mr Rushdie, but I'm afraid it's the combination of both, our diversity and similarities, which makes us resilient as a human race.

The countries that learn to make the best of both our differences and common traits, celebrating their national specificity and plurality, as much as their coincidences with "the others", building bridges rather than divides, will lead this world. We are all cultural hybrids and need each other to succeed. It's time that we turned that into a source of strength!

@OECD Observer No 314 Q2 2018

Adapted from the secretary-general's opening remarks to the OECD Forum, 29 May 2018. For the full original version, see: http://www.oecd.org/about/secretarygeneral/sg-opening-remarks-oecd-forum-france-may-2018.htm

Twitter:@A_Gurria

www.oecdobserver.org/angelgurria

www.oecd.org/about/secretary-general 